\title{
Upgradation of Hanau Spring Bow with Digital Inclinometer - A Report
}

\section{Anusha Borra ${ }^{1}$, K Chandrasekharan Nair ${ }^{2 *}$, MC Suresh Sajjan ${ }^{3}$, D Bheemalingeswara Rao ${ }^{4}$ and AV Rama Raju ${ }^{5}$}

${ }^{1}$ Postgraduate Student, Department of Prosthodontics, Vishnu Dental College,

Bhmavaram, AP, India

${ }^{2}$ Professor Emeritus, Department of Prosthodontics, Sri Sankara Dental College,

Akathumuri, Trivandrum, Kerala, India

${ }^{3}$ Professor of Prosthodontics and Principal, Vishnu Dental College, Bhimavaram, AP,

India

${ }^{4}$ Professor, Department of Prosthodontics, Vishnu Dental College, Bhimavaram, AP,

India

${ }^{5}$ Professor of Prosthodontics and Vice Principal, Vishnu Dental College, Bhimavaram,

AP, India

*Corresponding Author: K Chandrasekharan Nair, Professor Emeritus, Department

of Prosthodontics, Sri Sankara Dental College, Akathumuri, Trivandrum, Kerala,

India.
Received: August 20, 2021

Published: September 18, 2021

(C) All rights are reserved by

K Chandrasekharan Nair., et al.

\section{Abstract}

Face bow transfer has been in popular use in clinical prosthodontics and in the treatment planning of orthognathic surgery. Face bows have been subjected to an evolutionary process for bringing in precision and ease of operation. Spring bow stands testimony to such an evolution. Attempts have been made to optimize the precision of Spring bow and this article reports the incorporation of a digital inclinometer for enhancing the precision in the relationship of Spring bow with the Frankfort Horizontal plane.

Keywords: Face Bow; Spring Bow; Spirit Level; Digital Inclinometer; FH Plane; Third Point Reference

\section{Introduction}

Clinical prosthodontic procedures utilizing semi adjustable articulators for the establishment of correct plane of occlusion makes use of a third point of reference on the Frankfort horizontal plane. Use of this point orients the maxillary cast to the upper member of the articulator as the maxillae are oriented to the Frankfort horizontal plane (Figure 1 and 2). The generally accepted third point of reference is orbitale which is located at the deepest curvature of the lower border of the orbit. Transfer of the maxillary cast to the articulator using a face-bow also ensures a reliable three dimensional positioning of the maxillary cast in relation to the intercon- dylar hinge axis. The hinge axis position is arbitrarily located at a point, $13 \mathrm{~mm}$ anterior on a line drawn from the midposterior border of the tragus to the outer canthus of the eye (Beyron's point). This point has limitations and will never ensure the required relationship between the maxillary cast and the Frankfort Horizontal plane (FH plane). Frankfort plane is reliably established by drawing a line from the uppermost point

on the bony auditory meatus (porion) to the lowest point at the bony orbit (orbitale) in the cephalometric radiographs. Earpiece face bows are more accurate in establishing a faithful relationship to the FH plane than the Fascia face bows [1,2]. 


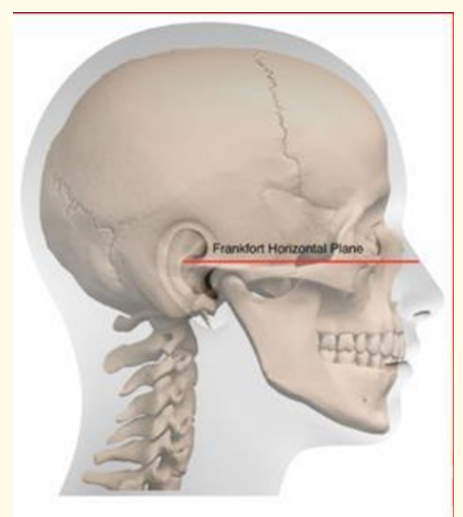

Figure 1: Frankfort horizontal plane marked on skull.

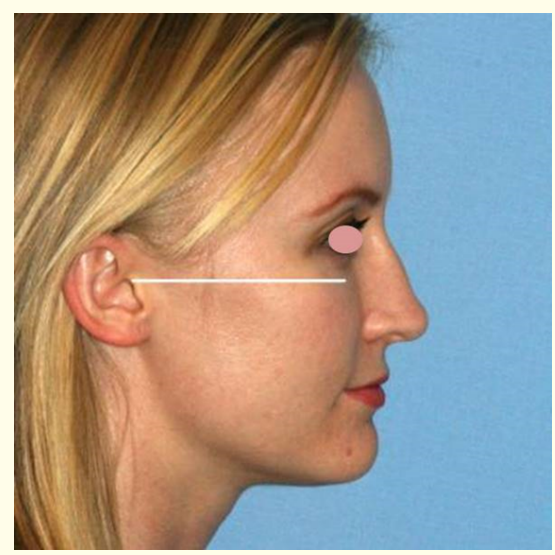

Figure 2: Frankfort horizontal plane marked on the face.

Hanau Spring bow is a popular earpiece face bow with unique features. It automatically centers (self-centering spring) and records the relationship of a patient's maxillary arch to the condyles with much ease. The earplugs get easily seated and the position of which is verifiable even by the patient on repeated use. The spring has the orbital pointer attached to the upper border of the bow. When correctly positioned relating both the auditory meatus and the orbitale, the upper border of the bow falls on the FH plane. The spring bow comes with a transfer clamp assembly, mounting platform with built-in cast support, bite fork and bite plane. The manufacturer has assured autoclavability. Spring bow allows easy indirect transfer especially with Hanau wide view articulator (Figure 3 and 4).

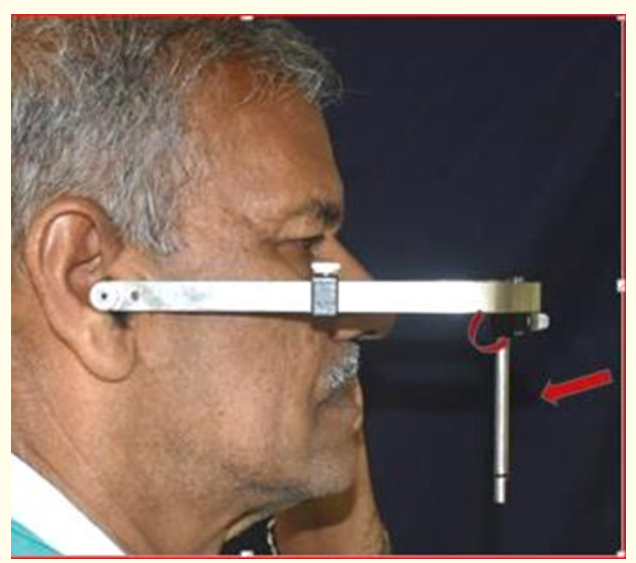

Figure 3: While doing face bow transfer, the spring bow coincides with FH plane and the transfer rod becomes vertical.

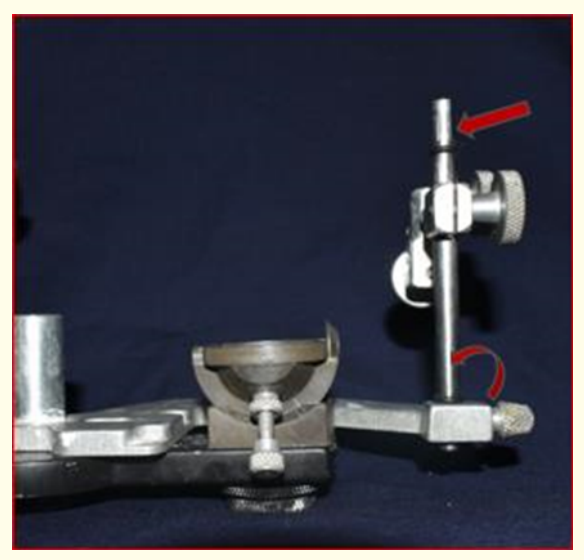

Figure 4: Transfer jig attached to the articulator receives vertical transfer rod.

When face bow transfer is done with Spring bow, it is directly related to the $\mathrm{FH}$ plane and logically it has to be made horizontal. This has to correspond with the natural head position which by definition is a standardized, reproducible, upright head position with the eyes focused on a point in the distance at the eye level. It is implied that the visual axis is horizontal and the FH plane assumes horizontality. By sitting in a dental chair, the natural head position cannot be achieved. Hence it is desirable to make the patient sit on a stool or a chair without head rest while doing face bow transfer [3]. 
After relating the face bow to the FH plane, it has to be positioned horizontal. Only visual judgment is made by practitioners and it cannot be claimed as accurate. When the upper jaw is connected to the face bow through the fork and the transfer clamp assembly, the horizontality gains importance. The rod of the transfer assembly becomes vertical when it is connected to the face bow. Only after that the clutches are tightened. After removing the rod from the face bow with the assembled fork, it is connected to the mounting platform (transfer jig) positioned in the articulator. The transfer jig will receive only vertically placed rod of the transfer clutch assembly. Perfect horizontality of the spring bow and the perpendicularity of the transfer rod are important factors to ensure a perfect relationship between the hinge axis and the upper jaw. About this Ellis stated in the context of orthognathic surgery 'This is important not only in prosthodontic treatment but in orthognathic treatment also. The more accurately the maxillary model is mounted with respect to the true hinge axis, the more accurate will be the information provided about the horizontal and vertical movements of the jaws during model surgery necessitated in connection with orthognathic treatment planning and prediction of treatment outcome' [4].

\section{Improving the design of spring bow}

A good attempt has been made by Sadhvi KV., et al. to incorporate Spirit level tools to the Spring bow so that assessment of horizontality becomes easy (Figure 5 and 6 ). This is followed in many teaching institutions. Spirit level tools indicate the horizontality through the position of a bubble and a fairly good amount of approximation creeps in to this method also [5]. The present article is an attempt to incorporate a digital inclinometer to verify the horizontality of the Spring bow when the face bow transfer is done. A calibrating device was also developed by the authors to verify the accuracy of the inclinometer.

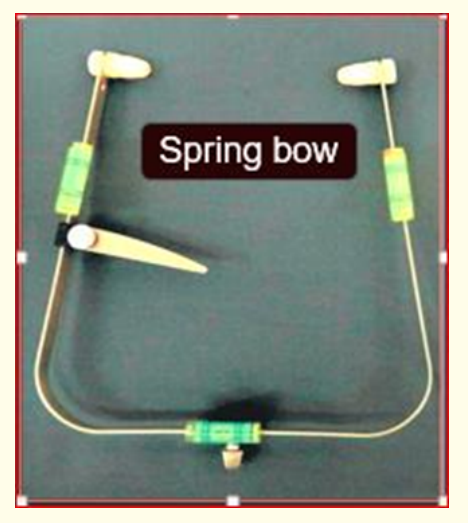

Figure 5: Hanau spring bow with attached spirit levels.

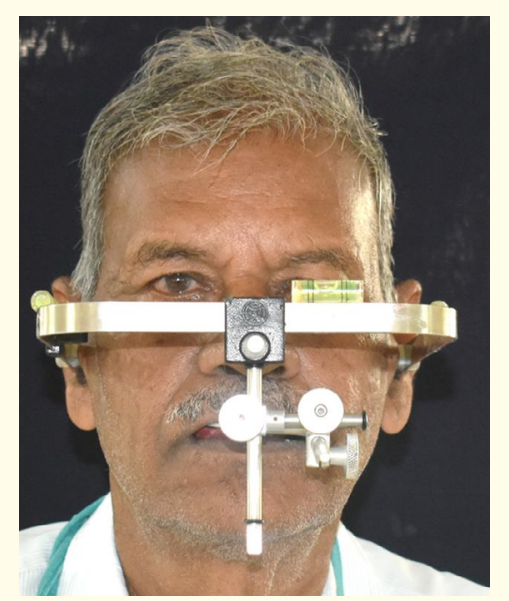

Figure 6: Face bow transfer using Hanau spring bow.

\section{Digital inclinometer/Digital protractor}

A digital inclinometer was procured (amicismart Digtal protractor) (Figure 7). Digital Inclinometers, which are commonly used in civil engineering projects, measure an object's orientation angle with respect to the force of gravity. This is done by means of an accelerometer, which monitors the effect of gravity on a tiny mass suspended in an elastic support structure. When the device tilts, this mass will move slightly, causing a change of capacitance between the mass and the supporting structure. The tilt angle is calculated from the measured capacitances.

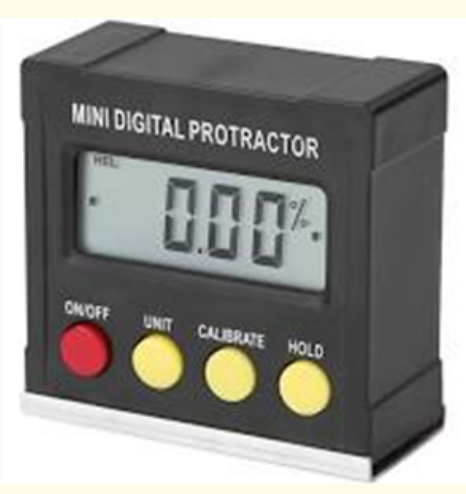

Figure 7: Digital inclinometer.

A calibrating device was designed which consisted of two glass plates and a protractor. The glass plates could be fixed at predetermined angulations with the aid of the protractor and the inclination could be verified with digital inclinometer (Figure 8 and 9). The glass plates were fixed at different angles from 0 to $40^{\circ}$ and the digital instrument proved to be accurate. 


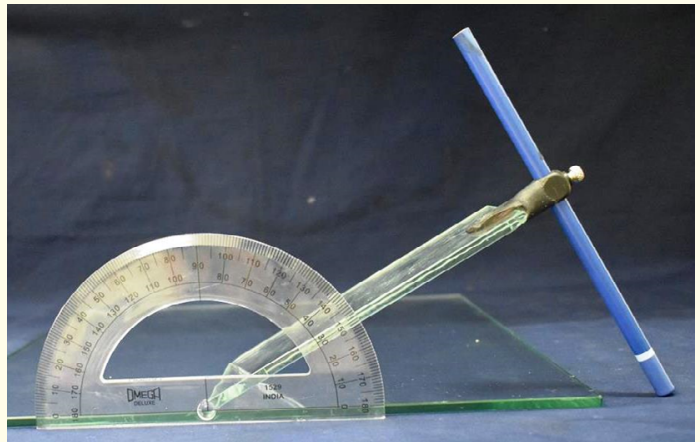

Figure 8: Digital inclinometer.

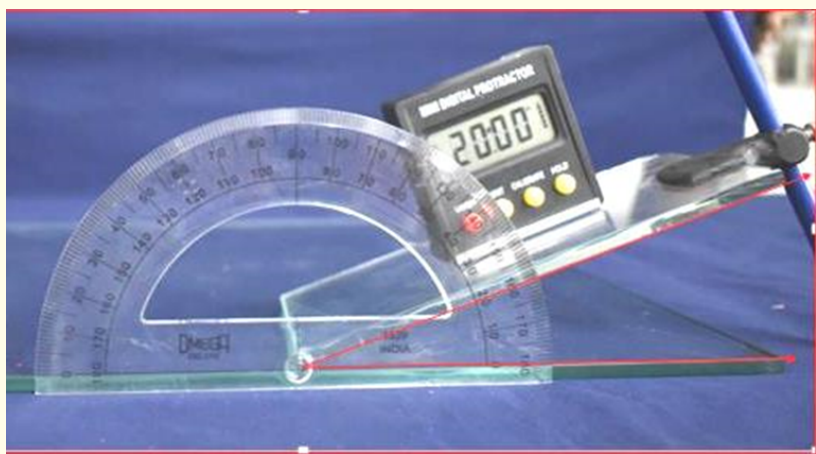

Figure 9: Calibration of inclinometer.

The inclinometer weighs only $38 \mathrm{~g}$. It has a built in magnet at the base and could easily be attached to the spring bow (Figure 10). Incorporation of digital inclinometer to the Spring bow ensured perfect horizontality with much ease and precision. A number of cases were completed with digital inclinometer and all the operators found it much convenient. Patients also reported no inconvenience. In future cephalometric based accuracy studies are planned [6].

\section{Conclusion}

Spring bow is rated as an arbitrary clinical and academic tool used in clinical prosthodontics and in predicting outcomes of orthognathic surgery. Incorporation of an inclinometer reduces the arbitrariness of the spring bow considerably.

\section{Bibliography}

1. Bailey J Jr and Nowlin TP. "Evaluation of the third point of reference for mounting maxillary casts on the Hanau articulator". Journal of Prosthetic Dentistry 51.2 (1984): 199-201.

2. Pittayapat P., et al. "Three-dimensional Frankfort horizontal plane for 3D cephalometry: a comparative assessment of conventional versus novel landmarks and horizontal planes". European Journal of Orthodontics 40.3 (2018): 239-248.

3. Meiyappan., et al. "Natural head position: An overview". Journal of Pharmacy and Bioallied Sciences 7.2 (2015): S424-S427.

4. Edward ellis III., et al. "Accuracy of Face-bow Transfer: Effect on Surgical Prediction and Postsurgical Result". Journal of Oral and Maxillofacial Surgery 50 (1992): 562-567.

5. Sadhvi K V. "Spirit level markers for face bow articulation". Kerala Dental Journal 32.2 (2009): 75-76.

6. Jaime Gateno Kim K and Forrest Brian Camp. "A Comparison of 3 Methods of Face-Bow Transfer Recording: Implications for Orthognathic Surgery". Journal of Oral and Maxillofacial Surgery 59 (2001): 635-640.

Volume 5 Issue 10 October 2021

(C) All rights are reserved by $\mathrm{K}$ Chandrasekharan

Nair., et al.

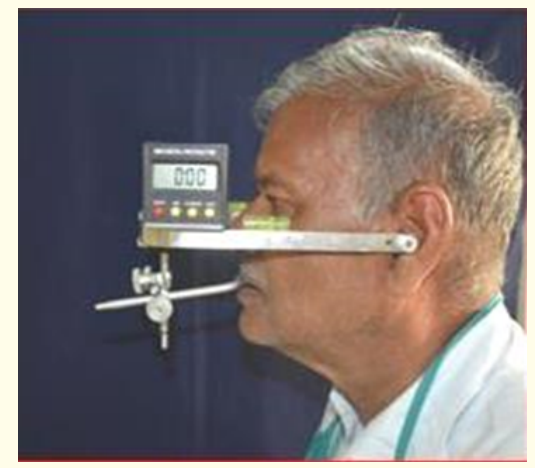

Figure 10: Digital inclinometer fixed on the Spring bow. 